\title{
Systemic Delivery of the Interleukin-1 Receptor Antagonist Protein Using a New Strategy of Direct Adenoviral-Mediated Gene Transfer to Skeletal Muscle Capillary Endothelium in the Isolated Rat Hindlimb
}

\author{
THEODORE H. WELLING, ${ }^{1}$ BEVERLY L. DAVIDSON, ${ }^{4}$ JENNIFER A. ZELENOCK, ${ }^{1}$ \\ JAMES C. STANLEY, ${ }^{1}$ DAVID GORDON,${ }^{2}$ BLAKE J. ROESSLER,${ }^{3}$ and LOUIS M. MESSINA ${ }^{5}$
}

\begin{abstract}
Current gene therapy strategies using adenoviral vectors to target the lung or liver have been complicated by an acute inflammatory response that can result in loss of transgene expression as well as tissue injury and necrosis. Skeletal muscle comprises $40 \%$ of total body weight; it possesses a high density, accessible capillary network that is resistant to injury and thus may be a logical target for adenoviral vectors. We hypothesized that adenoviral transduction of the rat skeletal muscle capillary bed during vascular isolation would achieve efficient gene transfer sufficient to achieve systemic serum levels of a recombinant protein without significant tissue injury. During vascular isolation of the hindleg, a replication-incompetent adenovirus (Ad) encoding for either the marker gene, human placental alkaline phosphatase (hpAP), or interleukin-1 receptor antagonist (IL-1ra) was infused and subsequently flushed from the circulation after a 30-min dwell period. Gene transfer over a $10^{9}-10^{12}$ particle/ml range to the gastrocnemius capillary endothelium and muscle fibers was highly efficient and titer-dependent, reaching maximum transduction rates of $71 \pm 7 \%$ and $25 \pm 5 \%$, respectively, 5 days after gene transfer $(n=3-8$ rats/group, $p<0.05)$. hpAP transgene expression was barely detectable at 14 days. No significant tissue injury or necrosis of the skeletal muscle was observed at 5 and 14 days, and distant organ gene transfer was minimal or absent. Gastrocnemius muscle from rats $(n=4)$ given Ad-IL-1ra had $241 \pm 66 \mathrm{pg}$ IL-1ra/mg protein at 5 days, while those given Ad-hpAP, negative control $(n=$ 3) had $35 \pm 14 \mathrm{pg}$ IL-1ra/mg protein $(p<0.05)$. Ad-IL-1ra rats $(n=4)$ had serum levels of $185 \pm 20 \mathrm{pg} / \mathrm{ml}$ IL-1ra at 5 days whereas Ad-hpAP control rats $(n=5)$ had no IL-1ra detectable $(p<0.0001)$. Athymic rats given Ad-IL-1ra $(n=6)$ had serum levels of $493 \pm 62 \mathrm{pg} / \mathrm{ml}$ IL-1ra 14 days after transduction, and IL-1ra was detected for up to 98 days. Sera from Ad-IL-1ra athymic rats significantly inhibited IL-1 $\beta$-induced (1 $\mathrm{ng} / \mathrm{ml})$ prostaglandin $\mathrm{E}_{2}\left(\mathrm{PGE}_{2}\right)$ production from cultured endothelial cells by $82 \pm 2 \%(p<0.001)$. Thus, this gene transfer strategy is the first to result in substantial transduction of both skeletal muscle capillary endothelium and fibers, sufficient to achieve pharmacologic levels of IL-1ra. Although no acute tissue injury or necrosis was observed, persistence of transgene expression in athymic rats suggests that loss of expression in normal rats was by an immune-mediated mechanism.
\end{abstract}

\section{OVERVIEW SUMMARY}

Here we report highly efficient adenoviral-mediated gene transfer to the rat skeletal muscle capillary endothelium and muscle fibers during vascular isolation of the hindlimb.
Gene transfer over a $10^{9}-10^{12}$ particle/ml range to the gastrocnemius capillary endothelium and muscle fibers is highly efficient and titer dependent, reaching maximum transduction rates in these tissue of $71 \pm 7 \%$ and $25 \pm 5 \%$, respectively, 5 days after gene transfer. Adenovirus-induced

Departments of ${ }^{1}$ Surgery, ${ }^{2}$ Pathology, and ${ }^{3}$ Internal Medicine, University of Michigan Medical School, Ann Arbor, MI 48109.

${ }_{4}^{4}$ Department of Internal Medicine, University of Iowa College of Medicine, Iowa City, IA 52242.

${ }^{5}$ Department of Surgery, University of California, San Francisco, San Francisco, CA 94143. 
inflammation in the skeletal muscle was not observed and distant organ gene transfer was minimal or absent. When adenoviral interleukin-1 receptor antagonist (Ad-IL-1ra) was used to transduce the gastrocnemius capillary endothelium and muscle fibers, serum IL-1ra levels were $185 \pm 20 \mathrm{pg} / \mathrm{ml}$. Athymic rats given Ad-IL-1ra had serum levels of $493 \pm 62 \mathrm{pg} / \mathrm{ml}$ IL-1ra 14 days after transduction and IL-1ra was detected for up to 98 days. This gene transfer strategy results in substantial transduction of capillary endothelium as well as skeletal muscle fibers sufficient to achieve pharmacologic levels of recombinant protein without evidence of local tissue injury.

\section{INTRODUCTION}

D EVELOPMENT OF EFFICIENT TECHNIQUES OF GENE TRANSFER and elucidation of the molecular basis for both acquired and hereditary human diseases have made gene therapy possible. However, development of a safe and efficient gene delivery strategy and identification of optimal target cells in vivo have lagged behind these advances in molecular biology. Recently, replication-incompetent adenoviral vectors have been introduced as a highly efficient technique of gene transfer. Adenoviral vectors are available in high titers, infect a broad range of cells, and do not require target cell replication for successful gene transfer. However, a disadvantage of adenoviral vectors is that they can induce an inflammatory reaction that can result in tissue injury or necrosis and loss of transgene expression when either delivered systemically or directly to vital organs such as the lung, liver, and brain (Davidson et al., 1994; Engelhardt et al., 1994; Simon et al., 1993; Yang et al., 1994a,b; McCray et al., 1995).

Endothelial cells are considered an excellent target for gene transfer because they represent a durable tissue located strategically at the blood tissue interface. A number of investigators have successfully transduced the endothelium of large muscular arteries (Nabel and Nabel, 1994; Messina et al., 1995). However, muscular arteries form only a small portion of the surface area of the circulatory system, and the number of transduced endothelial cells within such segments might be insufficient for the purposes of systemic gene therapy. Alternatively, capillaries comprise $80 \%$ of the circulatory system surface area and thus are a logical site for recombinant protein production to achieve either a regional or systemic therapeutic effect (Guyton, 1991; Messina et al, 1992). Skeletal muscle, accounting for $40 \%$ of total body weight (Guyton, 1991), possesses a high-density, accessible capillary network, that is relatively resistant to ischemic injury. Furthermore, skeletal muscle, similar to the liver, is capable of regeneration after a variety of injuries (Carlson et al., 1990). Skeletal muscles may be more easily targeted with less risk of morbidity than other tissues such as the lung and liver.

Here, we report the first highly efficient strategy of direct, adenovirus-mediated gene transfer to skeletal muscle capillary endothelium during vascular isolation of the hindleg. Additionally, significant gene transfer to the skeletal muscle fibers was also achieved. This technique of direct gene transfer to capillary endothelium during vascular isolation permitted the use of high-titer adenovirus $\left(10^{12}\right.$ particles $\left./ \mathrm{ml}\right)$, without evidence of acute muscle injury or necrosis, and resulted in minimal distant organ transduction. Using this technique, we achieved high serum concentrations of $\mathrm{IL}-1$ receptor antagonist protein (IL-lra), a clinically important inhibitor of $\mathrm{LL}-1$ 's deleterious actions in shock, inflammation, and rheumatoid arthritis (Dinarello, 1994). The serum concentrations of $\mathrm{L}$-l ra were bioactive and sufficient to inhibit $\Pi \mathrm{L}-1 \boldsymbol{\beta}$-induced prostaglandin $\mathrm{E}_{2}\left(\mathrm{PGE}_{2}\right)$ secretion by rat aortic endothelial cells in vitro. Transgene expression was documented for up to 98 days in athymic rats but nearly absent by 14 days in normal rats, suggesting that loss of transgene expression in normal rats was immune mediated. This strategy of direct gene transfer to the isolated skeletal muscle capillary bed may have wide applicability to gene therapy for acquired and inherited human diseases.

\section{METHODS}

\section{Recombinant adenoviral vectors}

The Escherichia coli lacZ (Davidson et al., 1994), human placental alkaline phosphatase (hpAP) (Muller et al., 1994), or the human I-1ra (Roessler et al., 1995) replication-incompetent recombinant adenoviral vectors were generated as described previously (Roessler et al., 1995). Briefly the appropriate cDNA and Rous sarcoma virus (RSV) promoter were cloned into the parent plasmid pAd.Bgl II to generate a proviral plasmid pAd.RSVlacZ, pAd.RSVhpAP, pAd.RSVIRAP. Each plasmid was linearized by Nhe I digestion and co-transfected into permissive 293 cells with adenoviral genomic DNA (Ad5 derivative sub 360, E-1 region deleted). As a result of homologous recombination, an E1A/E1B-deleted recombinant adenovirus containing the appropriate cDNA was produced. Thus, all adenoviral vectors were identical except for the particular cDNA, all of which were under transcriptional control of the RSV promoter. Purified adenovirus, harvested from 293 cells, was suspended in phosphate-buffered saline (PBS). Concentrations (particles $/ \mathrm{ml}$ ) were determined by the O.D.260 (1.0 OD U $=1.0 \times 10^{12}$ particles/ml) and were always found to be greater than $1.0 \times 10^{12}$ particles $/ \mathrm{ml}$ for each adenoviral preparation. A typical adenoviral preparation of $1.0 \times 10^{12}$ particles $/ \mathrm{ml}$ resulted in a titer of $1.0 \times 10^{11}$ plaque-forming units/ml. Fresh adenovirus was used immediately following preparation in all experiments.

\section{Hindlimb capillary bed isolation}

Male Wistar (WI/HICKSCAR) rats or athymic nude rats (225-325 grams) were anesthetized using $50 \mathrm{mg} / \mathrm{kg}$ ketamine hydrochloride and $25 \mathrm{mg} / \mathrm{kg}$ xylazine (I.M.) and were maintained under $2 \%$ isoflurane in oxygen. The common femoral artery, vein, and nerve were isolated through a groin incision, and a tourniquet was passed beneath them to encircle the entire proximal hindlimb. The saphenous artery was ligated distally and cannulated in a retrograde manner with a $26 \mathrm{G}$ needle connected to polyethylene tubing, which was preflushed with heparinized PBS $(100 \mathrm{U} / \mathrm{ml})$. Fifty units of heparin were then infused through the cannula prior to occluding hindlimb blood flow. Vascular isolation was achieved by occluding the common femoral, saphenous, and epigastric arteries and veins using microvascular clamps. Collateral flow was abolished by 
tightening the tourniquet around the proximal hindlimb. A venotomy was made in the distal saphenous vein to serve as outflow for flushing the hindlimb capillaries. Ten milliliters of warm PBS were then used to flush blood out of the capillaries before occluding the venotomy site. The appropriate titer of hpAP adenovirus (Ad-hpAP), $10^{12}$ particles/ml. IL-1ra adenovirus (Ad-IL-1ra), $10^{12}$ particles/ml LacZ adenovirus (AdlacZ, vector sham), or PBS (sham) was subsequently infused $(0.7 \mathrm{ml})$ into the hindlimb and allowed to incubate for $30 \mathrm{~min}$. Preliminary experiments showed this time interval to yield maximal transduction efficiency (data not shown). Following this incubation, the clamp was removed from the venotomy site, residual virus was washed from the capillaries, the cannula was removed, and the saphenous artery and vein were ligated. All other microvascular clamps were removed, thereby restoring antegrade arterial and venous flow. The incision was closed and the rat was recovered from anesthesia. All animal procedures were approved by the University of Michigan Committee on the Use and Care of Animals.

\section{Histological staining for hpAP transgene expression}

Five or 14 days following Ad-hpAP gene transfer, the rats were reanesthetized and the hindlimb capillaries were flushed and perfusion fixed $(120 \mathrm{mmHg}$ ) with $2 \%$ formaldehyde in PBS via the iliac artery. The muscles of the rat hindlimb were excised and placed in $2 \%$ formaldehyde. Biopsies of the lung, liver, spleen, testis, and brain were obtained and fixed in $2 \%$ formaldehyde. After $24 \mathrm{~h}$, these tissues were transferred to $70 \%$ ethanol. They were subsequently paraffin embedded, sectioned, and stained for heat-stable AP activity as previously described (Fields-Berry et al., 1992; Muller et al., 1994). All tissues were heated to $56^{\circ} \mathrm{C}$ for $60 \mathrm{~min}$ to inactivate endogenous AP activity. Abolition of endogenous AP activity was confirmed by histologic examination. Ad-lacZ-transduced tissues and PBS tissues served as negative controls for AP staining. Routine histological staining was performed using hematoxylin and eosin.

\section{Reverse transcriptase polymerase chain reaction for hpAP transgene expression in skeletal muscle and distant organs}

Tissues obtained for reverse transcriptase polymerase chain reaction (RT-PCR) analysis of hpAP expression were freshfrozen in liquid nitrogen and stored at $-70^{\circ} \mathrm{C}$. Total RNA was isolated from $50 \mathrm{mg}$ of each tissue and extracted using a MicroScale Total RNA Separator Kit according to the manufacturer's instructions (Clontech, Palo Alto, CA). Pure RNA was reverse transcribed using a 1st strand cDNA Synthesis Kit also according to the manufacturer's instructions (Clontech). The primers, 5'-TGGGGCCCTGCATGCTGCTGCTGCTGCTGC-3' (nucleotides 5-34) and 5'-TAGGATCCTGGCAGCTGTCACCGTAGACAC-3' (nucleotides 212-231), were used to amplify a 226-bp fragment of the hpAP cDNA (Muller et al., 1994). The PCR reactions were run in a 50- $\mu$ l volume and included $2 \mu \mathrm{l}$ of the cDNA synthesis product, $250 \mathrm{ng}$ of each primer, 1.6 units of Taq polymerase (Perkin-Elmer Cetus, Norwalk, CT), $2 \mathrm{mM}$ dNTPs (Invitrogen), and $2.0 \mathrm{mM} \mathrm{MgCl}$ (in Buffer $\mathrm{N}$, Invitrogen) at a $\mathrm{pH}$ of 10 . An initial denaturing period of $5 \mathrm{~min}$ at $94^{\circ} \mathrm{C}$ was performed by 35 cycles of denaturing for $40 \mathrm{sec}$ at $94^{\circ} \mathrm{C}$ and an- nealing/extension for $40 \mathrm{sec}$ at $58^{\circ} \mathrm{C}$ and $40 \mathrm{sec}$ at $72^{\circ} \mathrm{C}$. Glyceraldehyde phosphate dehydrogenase (GAPDH) expression was measured, as previously described (Mata et al., 1993), using RT-PCR to validate that the RNA extraction and cDNA synthesis procedures were adequate to provide pure RNA and cDNA, respectively.

\section{Detection of recombinant $I L$-Ira in serum and skeletal muscle}

A commercial ELISA kit for human recombinant IL-1ra was used to measure IL-1ra in peripheral venous serum or in whole muscle extracts according to the manufacturer's instructions (R\&D Systems, Minneapolis, MN). Peripheral venous serum was saved at $-70^{\circ} \mathrm{C}$ until ELISA. Whole gastrocnemius muscle samples were fresh-frozen in liquid nitrogen and stored at $-70^{\circ} \mathrm{C}$ until protein extraction (Dhawan et al., 1991) and ELISA. Total protein was determined using the bicinchoninic acid method (Pierce Chemical, Rockford, IL). IL-1ra was quantitated using a standard curve diluted in normal rat serum (for serum samples) or diluted in muscle extraction buffer (for muscle samples). The assay for $\mathrm{PGE}_{2}$ is sensitive down to a concentration of $1.5 \mathrm{pg} / \mathrm{ml} \mathrm{PGE}$ and exhibited $50 \%$ cross reactivity for $\mathrm{PGE}_{1}$. It exhibits less than $2 \%$ cross reactivity for all other ecinosoids.

\section{Detection of IL-Ira activity in peripheral serum}

Peripheral venous serum was added to confluent cultures of rat aortic endothelial cells (RAEC) (Magee et al., 1994) in the presence of $0.0,0.1$, or $1.0 \mathrm{ng} / \mathrm{ml}$ human $\mathrm{IL}-1 \beta$ for $6 \mathrm{~h}$ (Bull et al., 1990; Maier et al., 1990). RAEC were washed twice in serum-free low-glucose DMEM (GIBCO, Gaithersburg, MD), and the $\mathrm{PGE}_{2}$ released was collected in serum-free DMEM for $24 \mathrm{~h}$. $\mathrm{PGE}_{2}$ was assayed by an enzyme immunoassay according to the manufacturer's instructions (Perseptive Diagnostics, Cambridge, MA).

\section{Statistical analysis}

All data are expressed as the mean plus or minus the standard error of the mean (SEM). Statistical analysis was performed using analysis of variance (ANOVA) and a post hoc comparison between groups with Fisher's protected least squares difference test or a two-tailed Student's $t$-test (Devore, 1991) (Statview 4.0, Abacus Concepts, Inc., Berkeley, CA). Significance was assigned when the $p$ value was less than 0.05 .

\section{RESULTS}

Efficiency of adenoviral-mediated gene transfer to the skeletal muscle capillary endothelium

Highly efficient gene transfer to the capillary endothelium was achieved (Fig. 1A) by sustained exposure of the capillary endothelium to high-titer Ad-hpAP during vascular isolation of the rat hindlimb. Although at least some capillary endothelium transduction was achieved in all of the lower hindlimb muscles using $10^{12}$ particles/ml Ad-hpAP, the anterior tibialis and gastrocnemius demonstrated the highest transduction rates 5 days following vascular isolation, ranging from $1 \%$ to $35 \%$ and $33 \%$ 
to $88 \%$, respectively. In addition to transduction of the capillary endothelium, some transduction to arterioles and venules was also observed. However, by 14 days after gene transfer, hpAP activity was significantly reduced to levels less than $1 \%$ (data not shown). Due to the consistent transduction rate for the gastrocnemius capillary endothelium at 5 days, this muscle was studied at this time point in all subsequent experiments.

Capillary endothelium transduction rates were dependent upon the adenoviral titer (Fig. 1B). Capillary endothelium exposure to $10^{12}$ particles/ml Ad-hpAP resulted in transduction of $71 \pm 7 \%$ of the capillary endothelium. This rate fell substantially with decreasing titers to a rate of $2 \pm 0.3 \%$ at $10^{9}$ particles/ml. Unexpectedly, substantial gene transfer to the muscle fibers was also achieved by this strategy of vascular isolation (Fig. 1C). The transduction rate of $25 \pm 5 \%$ of the gastrocnemius muscle fibers achieved at a titer of $10^{12}$ particles $/ \mathrm{ml}$ fell to $0.5 \pm 0.3 \%$ at a titer of $10^{9}$ particles $/ \mathrm{ml}$.

Although the skeletal muscle capillary bed was exposed dur-
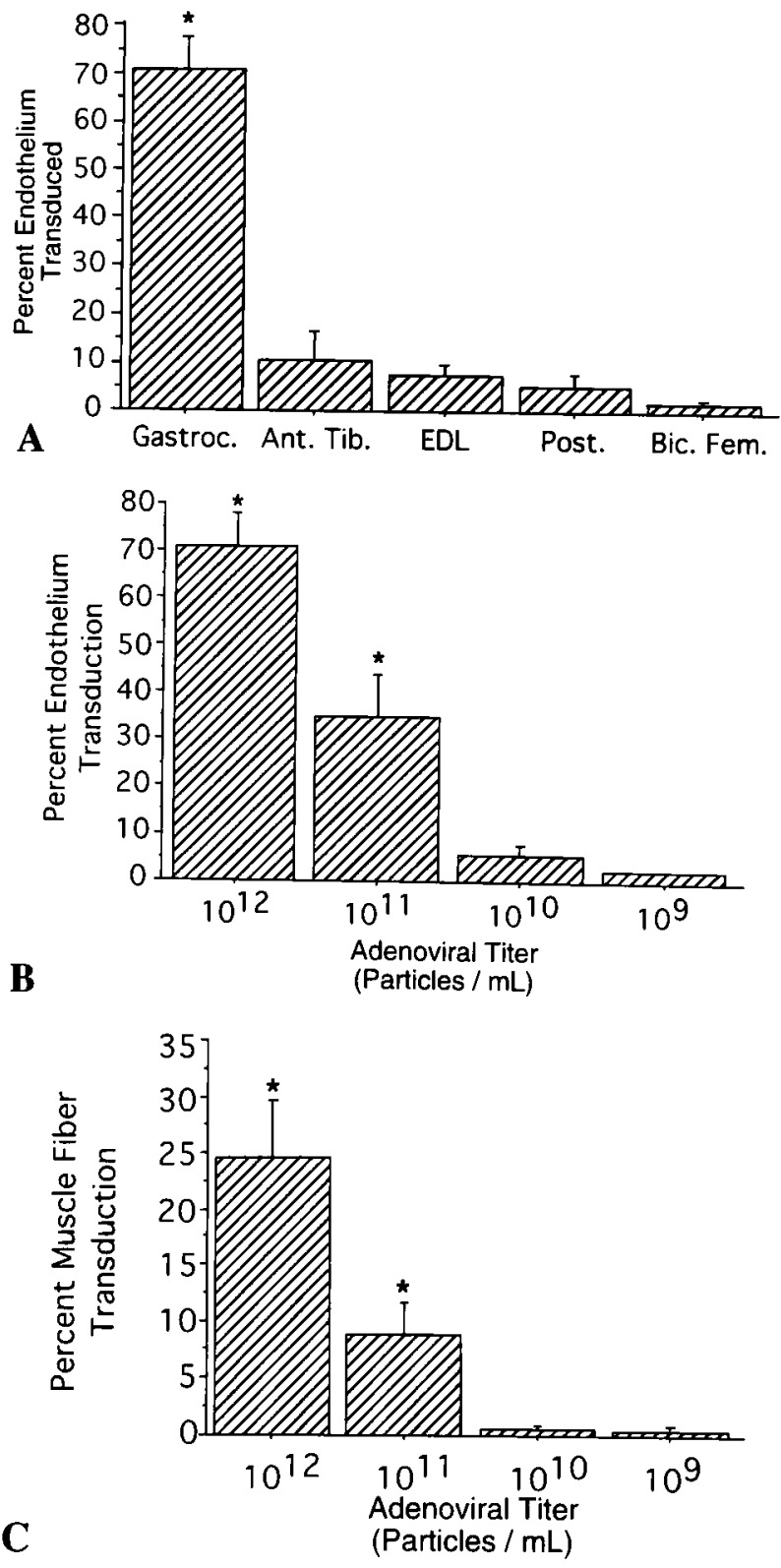

ing the 30-min vascular isolation to adenoviral titers of $10^{12}$ particles/ml, no evidence of significant acute tissue injury, necrosis, or other pathology was identified following systematic review of hemotoxylin and eosin-stained muscle sections at both 5 days (Fig. $2 \mathrm{~A}$ ) and 14 days (data not shown). The high transduction rates were identified based on the presence of purple-staining cells, indicative of heat-stable hpAP (Fig. $2 \mathrm{~B}, \mathrm{C})$. The purple staining was highly specific for hpAP because vascular hindlimb isolation and infusion of either PBS (vehicle sham, data not shown) or $10^{12}$ particles/ml Ad-lacZ (virus sham, Fig. 2D) did not demonstrate hpAP staining. The location of the endothelium in relation to the muscle fibers was defined (Fig. 2E) using the endothelial cell specific marker, Griffonia simplicifolia I lectin (Hansen-Smith et al., 1988).

\section{Specificity of adenoviral-mediated gene transfer to isolated skeletal muscle capillary endothelium}

Experiments were performed to determine the tissue specificity of this gene transfer strategy and to determine if any deleterious systemic effects resulted. RT-PCR detected hpAP expression in some distant organs of Ad-hpAP rats, being most common in the liver and spleen (Table 1). This occurred even though hindlimbs were isolated from the systemic circulation, as evidenced by strict localization of Evan's blue dye to the hindlimb (data not shown). However, hpAP protein in these distant organs was minimal, as determined histologically by hpAP staining (Table 1).

\section{Efficacy of adenoviral-mediated gene transfer to isolated skeletal muscle capillary endothelium for systemic delivery of recombinant proteins}

To evaluate the efficacy of transducing the capillary endothelium for systemic delivery of a soluble recombinant protein, a recombinant adenovirus containing the cDNA for human IL-1ra was used. Peripheral venous serum from rats transduced with Ad-IL-1ra contained high concentrations of human IL-1ra protein (Fig. 3A), whereas venous serum of rats transduced with

FIG. 1. Endothelium transduction rate in hindlimb skeletal muscles of Ad-hpAP-transduced rats. Transduction rate was determined as a percentage of the total muscle capillarys visualized in cross sections $(\mathrm{m} \pm \mathrm{SEM})$. A. Rats were given $10^{12}$ particles/ml of Ad-hpAP into the isolated hindlimb vasculature and the indicated muscle groups were assessed for histological evidence of hpAP activity 5 days later. The gastrocnemius muscle (Gastroc.) resulted in a higher transduction rate than that found in the anterior tibialis (Ant. Tib.), extensor digitorum longus (EDL), posterior muscles (Post.), or biceps femoris (Bic. Fem.). Five to eight Ad-hpAP-transduced rats were analyzed for each individual muscle shown above. ${ }^{*} p<0.0001$ versus all groups. B. Endothelium transduction rate as a function of titer in gastrocnemius muscle of Ad-hpAP transduced rats at 5 days. The gastrocnemius endothelium transduction rate was titer dependent with $10^{12}$ particles/ml, resulting in a maximal transduction rate. Gastrocnemius muscles from 3-8 Ad-hpAP-transduced rats were analyzed for each titer tested. ${ }^{*} p<0.05$ versus all other titers. C. Muscle fiber transduction rate as a function of titer in gastrocnemius muscle of Ad-hpAP-transduced rats at 5 days. The gastrocnemius muscle fiber transduction rate was titer dependent with $10^{12}$ particles $/ \mathrm{ml}$ resulting in a maximal transduction rate. Gastrocnemius muscles from 3-8 Ad-hpAP-transduced rats were analyzed for each titer tested. ${ }^{*} p<0.01$ versus all other titers. 
A

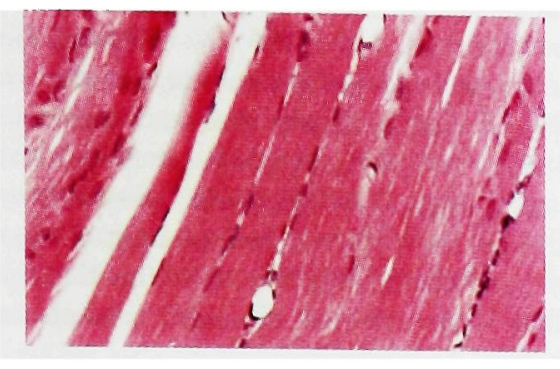

B

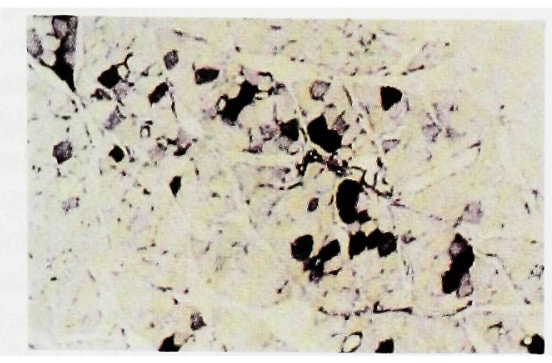

C

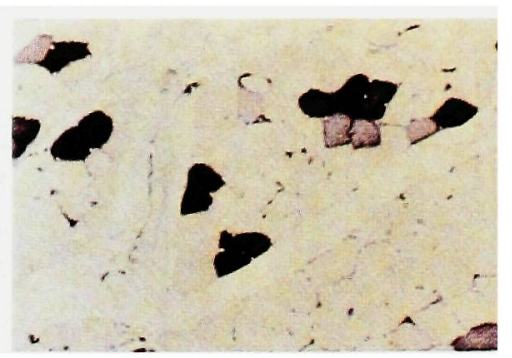

D

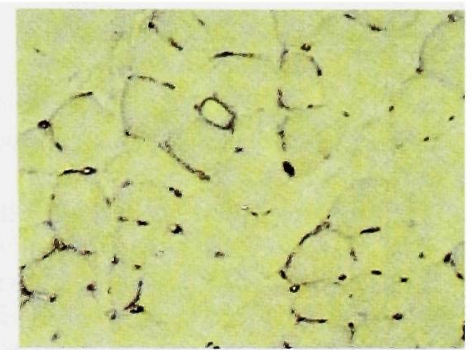

$\mathbf{E}$

FIG. 2. Histological examination of perfusion-fixed gastrocnemius muscle cross sections of rats 5 days after undergoing hindlimb vascular isolation to receive the indicated infusions. A. Hematoxyin and eosin staining 5 days following infusion of $10^{12}$ particles/ml of Ad-hpAP (40X) demonstrated no evidence of tissue injury, necrosis, or other obvious pathology. B and C. Heat-stable alkaline phosphatase staining (purple) indicative of hpAP activity 5 days following infusion of $10^{12}$ particles/ml of Ad-hpAP $(10 \times$ and $40 \times)$. Purple staining is evident in the endothelium and muscle fibers. D. Heat-stable alkaline phosphatase staining for hPAP activity 5 days following infusion of $10^{12}$ particles/ml of Ad-lacZ (40X) (virus sham, negative staining control). E. Nontransduced gastrocnemius muscle stained with the endothelial cell-specific Griffonia simplicifolia I lectin defining the location of the endothelium in relation to the muscle fibers $(40 \times)$.

Ad-hpAP adenovirus (negative control) had no detectable human IL-1ra at 5 days following gene transfer. Whole gastrocnemius muscle protein extraction from Ad-IL-1ra rats had $241 \pm 66 \mathrm{pg} \mathrm{IL}-1 \mathrm{ra} / \mathrm{mg}$ muscle protein, whereas Ad-hpAP rats (negative control) had $35 \pm 14 \mathrm{pg} \mathrm{IL}-1 \mathrm{ra} / \mathrm{mg}$ muscle protein (Fig. 3B), representing nonspecific cross-reactivity of the muscle's endogenous proteins to the IL-1ra ELISA.

Loss of transgene expression after adenoviral gene transfer is thought to be immune mediated (Simon et al., 1993; Engelhardt et al., 1994; Yang et al., 1994a,b; McCray et al., 1995). To determine if this might account for the loss of expression in rat endothelium and skeletal muscle using our strategy, the hindlimb skeletal muscle capillary endothelium in athymic rats was transduced with Ad- $\Pi$-1ra; these rats lack normal T lymphocyte function (Wahl et al., 1986). Peripheral venous serum was collected and IL-1ra concentrations in the athymic rats were compared to venous serum of normal rats that received Ad-IL-1ra (Fig. 4). In contrast to the near complete loss of detectable serum levels of $\mathrm{LL}-1 \mathrm{ra}$ in normal rats by 21 days following transduction, high $\mathrm{IL}-1$ ra serum concentrations were documented up to 98 days following transduction in athymic rats.

Finally, the bioactivity of IL-1ra in the sera was shown to establish the efficacy of this gene transfer strategy to deliver functional recombinant proteins to the systemic circulation. To achieve this, IL-1ra in the sera of IL-1ra transduced rats was assessed for its ability to inhibit $\Pi$ - $1 \boldsymbol{\beta}$-induced $\mathrm{PGE}_{2}$ secretion from RAEC. Following a co-incubation of sera from IL-1ratransduced rats with recombinant human $\mathrm{IL}-1 \beta, \mathrm{PGE}_{2}$ secre- tion was inhibited at all $\mathrm{IL}-1 \beta$ concentrations tested (Fig. 5) with an $82 \pm 2 \%$ inhibition of $1 \mathrm{ng} / \mathrm{ml} \mathrm{IL}-1 \beta(p<0.001)$, signifying that the IL-1ra was biologically active.

Table 1. Reverse Transcriptase PCR Assay FOR HPAP EXPRESSION IN DISTANT TISSUES

\begin{tabular}{lcc}
\hline Tissue & $\begin{array}{c}\text { Ratio of positive RT-PCR } \\
\text { samples per number studied }\end{array}$ & hpAP staining \\
\hline Gastrocnemius & $4 / 4$ & $71 \pm 7 \%$ \\
Liver & $3 / 4$ & $<1 \%$ \\
Spleen & $3 / 3$ & $<1 \%$ \\
Lung & $1 / 4$ & $<1 \%$ \\
Testis & $1 / 3$ & $<1 \%$ \\
Brain & $1 / 3$ & $<1 \%$
\end{tabular}

Normal rats were transduced with Ad-hpAP $\left(10^{12}\right.$ particles $/ \mathrm{ml}$ ) in the isolated skeletal muscle hindlimb and the indicated tissues were snap frozen 5 days later. Tissues were subsequently extracted for pure total RNA, reverse-transcribed into CDNA, and subjected to PCR using primers specific for the hpAP cDNA. PCR products were subjected to gel electrophoresis, stained with ethidium bromide, and visualized under UV light for the appropriately sized band. Normal rat tissue and lacZ transduced tissue served as internal assay negative controls. PCR reactions were also carried out using primers for GAPDH to verify the integrity of the RNA extraction and reverse transcription. hpAP protein activity was measured on identical tissue samples and the transduction rates determined using histological staining for hpAP as described in Fig. 1. 
A

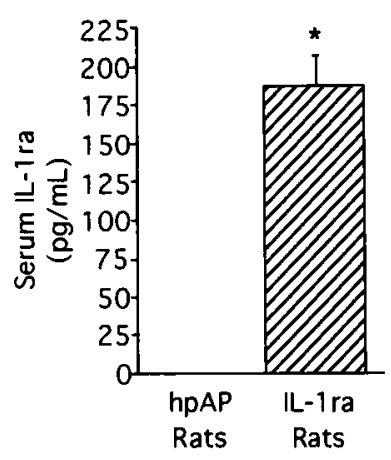

B

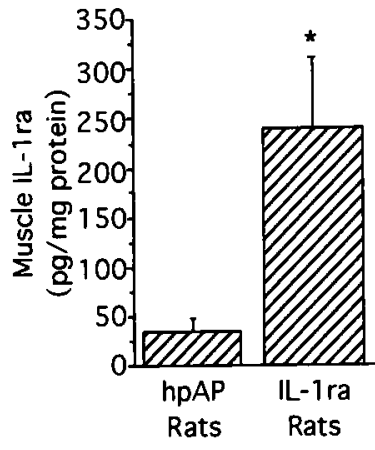

FIG. 3. Sera and muscle tissue IL-1 ra concentrations in AdIL-1ra-transduced rats. A. Serum human $\mathrm{L}-1$ ra protein concentrations as determined by ELISA in rats 5 days after undergoing hindlimb vascular isolation to receive either $10^{12}$ particles/ml Ad-IL-1ra (4 rats) or $10^{12}$ particles/ml Ad-hpAP (negative control, 5 rats). Significant levels of human IL-1ra were detected in the sera of Ad-IL-1ra-transduced rats. ${ }^{*} p<$ 0.0001 . B. Rats were treated identically as in A with either $10^{12}$ particles/ml Ad-IL-1ra (4 rats) or $10^{12}$ particles/ml Ad-hpAP ( 3 rats). Five days later the gastrocnemius muscle was extracted for protein, and human $\mathbb{L}$-1ra protein was measured by ELISA and normalized to total protein extracted. ${ }^{*} p<0.05$.

\section{DISCUSSION}

These results show for the first time highly efficient direct in vivo adenovirus-mediated gene transfer to the skeletal muscle capillary endothelium during vascular isolation. Not only was highly efficient gene transfer to the capillary endothelium achieved, but efficient gene transfer was also achieved to the muscle fibers (Fig. 1B,C). The expression in the skeletal muscle was found predominantly in the gastrocnemius (Fig. 1A). The localization of transgene expression in the gastrocnemius

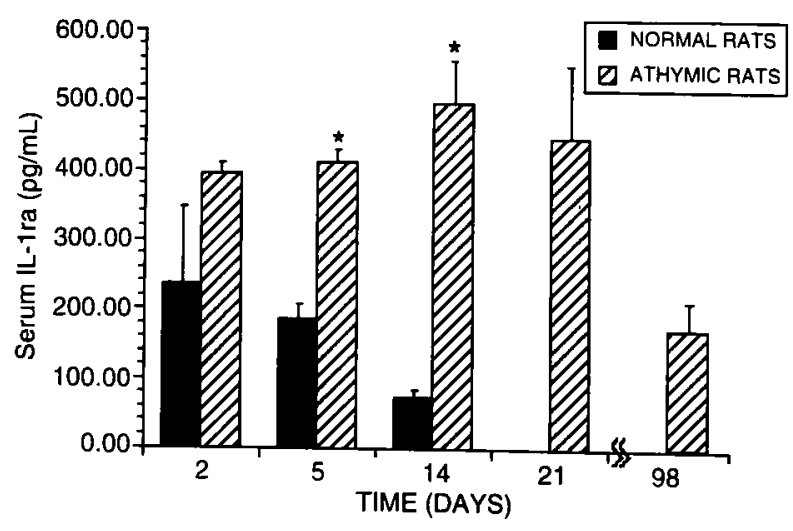

FIG. 4. Durability of $\mathbb{L}-1$ ra expression and systemic concentrations of $\mathbb{L}-1$ ra in Ad- $\mathbb{L}-1$ ra-transduced rats. Normal rats (3 rats) or athymic nude rats (6 rats) were treated with $10^{12}$ particles/ml Ad-IL-1ra and venous serum was measured for human IL-1ra protein as described in Fig. 5A at the indicated times post-transduction. Duration of $\mathbb{L}-1$ ra expression was significantly longer in athymic rats than in normal rats. ${ }^{*} p<0.005$ versus normal rat IL-1 ra concentrations.

muscle likely reflects differences in the volume distribution of the adenoviral perfusate in the static capillary bed during vascular isolation (Ooboshi et al., 1995). Nonetheless, these capillary endothelium and muscle fiber transduction rates were sufficiently high such that hindlimbs that were transduced with Ad-IL-1ra resulted in systemic serum IL-1ra concentrations as high as $185 \mathrm{pg} / \mathrm{ml}$ (Figs. 3 and 4), a level consistent with that observed following experimental endotoxemia (Granowitz et $a l ., 1991)$ and sufficiently bioactive to inhibit IL- $1 \beta$-induced $\mathrm{PGE}_{2}$ secretion from cultured rat aortic endothelial cells (RAEC) (Fig. 5).

This technique of gene transfer to skeletal muscle capillary endothelium and fibers during vascular isolation was accomplished with low peri-procedural morbidity and without evidence of acute tissue injury or necrosis in the target muscle 5 and 14 days after gene transfer. In addition, the vascular isolation technique provided significant protection of distant organs from high-titer adenovirus as transduction rates in these tissues were minimal $(0-1 \%)$ (Table 1$)$. Thus, this gene transfer strategy achieved two clinically important goals of absence of acute injury of the target tissue and minimal systemic exposure to high-titer adenovirus.

Adenoviral transduction of the lung and liver is associated with an inflammatory reaction with a lymphocytic infiltrate and necrosis (Simon et al., 1993; Yang et al., 1994a,b; Engelhardt et al., 1994; McCray et al., 1995). This inflammatory reaction due to wild-type and recombinant adenoviral vectors occurs within $48 \mathrm{hr}$ following adenovirus delivery in some experimental animals models (Yang et al., 1994a) and human trials. In this study, no evidence of skeletal muscle injury at either 5 or 14 days after exposure was observed. Thus, this study and others suggest that skeletal muscle may be more resistant to

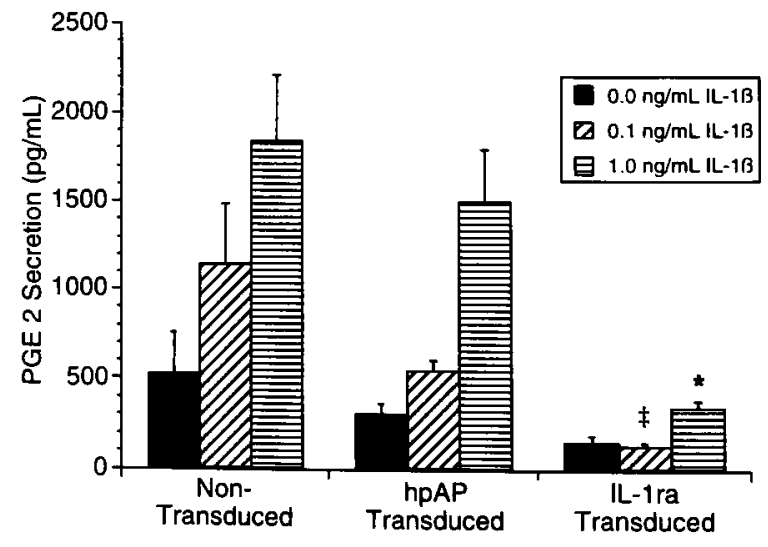

FIG. 5. IL-1ra bioactivity in sera from Ad-IL-1 ra-transduced rats. Athymic rats were transduced as described in Fig. 1 with Ad-hpAP (4 rats), Ad-I-1ra (6 rats), or nontransduced (4 rats). Sera were obtained from each animal and incubated with separate cultures of RAEC for $6 \mathrm{hr}$ in the presence of the indicated concentrations of human $\Pi L-1 \beta$ in serum-free DMEM. After 6 $\mathrm{hr}$, RAEC were washed and incubated in serum-free DMEM for $24 \mathrm{hr}$ to collect $\mathrm{PGE}_{2} ; \mathrm{PGE}_{2}$ was measured by immunoassay. Sera containing human $\mathrm{L}-1$ ra from Ad-IL-1ra-transduced athymic rats inhibited $\mathbb{L}-1 \beta$-induced $\mathrm{PGE}_{2}$ production from RAEC. ${ }^{*} p<0.0001$ and $\ddagger p<0.05$ versus Ad-hpAP-transduced rats and nontransduced rats. This inhibition was partially reversed by $1.0 \mathrm{ng} / \mathrm{ml}$ of IL- $1 \beta$. 
adenoviral-induced tissue injury than other organs such as the lung and liver (Ascadi et al., 1994; Fisher et al., 1994; Tripathy et al., 1994).

The longer duration of transgene expression in Ad-IL-1ra normal rats as well as the persistent expression of Ad- $\mathrm{LL}-1 \mathrm{ra}$ in athymic rats strongly suggests that an immune-mediated mechanism may be responsible for loss of transgene expression in normal rats. In Ad-hpAP normal rats, less than $1 \%$ of the endothelium and muscle fibers stained positively 14 days after adenoviral infusion. This transgene expression pattern is consistent with the findings of other investigators when using adenoviral vectors (Yao et al., 1995). Interestingly, at 14 days, AdIL-1ra normal rats showed reduced, yet significantly detectable, serum concentrations of human $\mathrm{L}-\mathrm{lra}$ (Fig. 4). Detectable systemic concentrations of human IL-1ra suggest fairly substantial endothelial and muscle fiber expression beyond that documented in Ad-hpAP rats at 14 days. One potential explanation for this discrepancy is that inhibition of $\mathrm{IL}-\mathrm{l}$-mediated events by IL-1ra may inhibit immune-mediated loss of transgene expression.

In experiments using athymic rats, we demonstrated longterm expression of human IL-l ra for at least 98 days (Fig. 4). Persistent transgene expression using these adenoviral vectors in athymic rats further supports the hypothesis that loss of transgene expression in normal rats may be directly or indirectly $\mathrm{T}$ cell mediated (Yang et al., 1994a,b; Yao et al., 1996). Because no significant acute tissue injury or necrosis was observed 5 or 14 days following transduction, the immune mechanism could be transgene specific. Nonetheless, it is now clear that duration of transgene expression after in vivo adenoviral transduction is species, organ, and, most likely, transgene specific.

Multiple clinical applications of this gene transfer strategy exist for the treatment of acquired or genetic disease. Durable expression of IL-1ra would have considerable potential for treating acquired human diseases characterized by chronic inflammation, such as rheumatoid arthritis and polymyositis. Transient IL-1ra expression might be applicable to the prevention of sepsis-induced acute respiratory distress syndrome or multiple organ dysfunction in which $\mathbb{L}-\boldsymbol{\beta}$ is critical to disease pathogenesis (Dinarello, 1994; Fisher et al., 1994).

Other transgenes could be used to achieve regional or systemic therapeutic effects. This technique's capacity to transduce multiple different muscles simultaneously within a limb may be particularly well suited to Duchenne's muscular dystrophy. This technique could also be used to achieve a regional effect, such as the induction of angiogenesis in a chronically ischemic limb or a systemic effect such as that required by the treatment of hemophilia A or B.

\section{ACKNOWLEDGMENTS}

This work was supported by National Institutes of Health grant HL-51184 (L.M.M.), VA Merit Review Grant (L.M.M.), and the Jobst Vascular Research Laboratory. B.L.D. is a fellow of the Roy J. Carver Charitable Trust. We thank Kay Cherian for preparing adenovirus; we also thank Minakshi Sarkar and Chuanfang Jin for assistance with RT-PCR.

This work was presented in part at the Federation of Experimental Biology Meeting, American Physiological
Society, April 9-13, 1995, and published in abstract form in FASEB J. 9, A314, 1995.

\section{REFERENCES}

ASCADI, G., AGNES, J., MASSIE, B., SIMONEAU, M., HOLLAND, P., BLASCHUK, K., and KARPARTI, G. (1994). A differential efficiency of adenovirus-medicated in vivo gene transfer into skeletal muscles of different maturity. Hum. Mol. Genet. 3, 579-584.

BULL, H.A., RUSTIN, M.H.A., SPAULL, J., COHEN, J., WILSONJONES, E., and DOWD, P.M. (1990). Pro-inflammatory mediators induce sustained release of prostaglandin E2 from human dermal microvascular endothelial cells. Br. J. Derm. 122, 153-164.

CARLSON, B.M., SHEPARD, B., and KOMOROWSKI, T.E. (1990). A histological study of local anesthetic-induced muscle degeneration and regeneration in the monkey. J. Orthop. Res. 8, 485-494.

DAVIDSON, B.L, DORAN, S.E., SHEWACH, D.S., LATTA, J.M., HARTMAN, J.W., and ROESSLER, B.J. (1994). Expression of Escherichia coli $\beta$-galactosidase and rat HPRT in the CNS of Macaca mulatta following adenoviral mediated gene transfer. Exp. Neurol. 125, 258-267.

DEVORE, J.L. (1991). Probability and Statistics for Engineering and the Sciences. (Brooks/Cole Publishing Co., Belmont, CA) 716 pp. DHAWAN, J., PAN, L.C., PAVLATH, G.K., TRAVIS, M.A., LANCTOT, A.M., and BLAU, H.M. (1991). Systemic delivery of human growth hormone by injection of genetically engineered myoblasts. Science 254, 1509-1512.

DINARELLO, C.A. (1994). Interleukin-1. Adv. Pharmacol. 25, 21-51. ENGELHARDT, J.F., YE, X., DORANZ, B., and WLSON, J.M. (1994). Ablation of E2A in recombinant adenoviruses improves transgene persistence and decreases inflammatory response in mouse liver. Proc. Natl. Acad. Sci. USA 91, 6196-6200.

FIELDS-BERRY, S.C., HALLIDAY, A.L., and CEPKO, C.L. (1992). A recombinant retrovirus encoding alkaline phosphatase confirms clonal boundary assignment in lineage analysis of murine retinal cells. Proc. Natl. Acad. Sci. USA 89, 693-697.

FISHER, C.J., DHAINAUT, J.A., OPAL, S.M., PRIBBLE, J.P., BALK, R.A., SLOTMAN, G.J., IBERTI, T.J., RACKOW, E.C., SHAPIRO, M.J., GREENMAN, R.L., REINES, H.D., SHELLY, M.P., THOMPSON, B.W., LABRECQUE, J.F., CATALANO, M.A., KNAUS, W.A., and SADOFF, J.C. (1994). Recombinant human interleukin 1 receptor antagonist in the treatment of patients with sepsis syndrome: results from a randomized, double-blind, placebo-controlled trial. J. Am. Med. Assn. 271, 1836-1843.

GRANOWITZ, E.V., SANTOS, A.A., POUTSIAKA, D.D., CANNON, J.G., WILMORE, D.W., WOLFF, S.M., and DINARELLO, C.A. (1991). Production of interleukin-1-receptor antagonist during experimental endotoxaemia. Lancet 338, 1423-1424.

GUYTON, A.C. (1991). Textbook of Medical Physiology. (W.B. Saunders Co., Philadelphia) 1014 pp.

HANSEN-SMITH, F.M., WATSON, L., LU, D.Y., and GOLDSTEIN, I. (1988). Griffonia simplicifolia I: Fluorescent tracer for microcirculatory vessels in nonperfused thin muscles and sectioned muscle. Microvasc. Res. 36, 199-215.

MAGEE, J.C., STONE, A.E., OLDHAM, K.T., and GUICE, K.S. (1994). Isolation, culture, and characterization of rat lung microvascular endothelial cells. Am. J. Physiol. 267, L433-L441.

MAIER, J.A.M., HLA, T., and MACLAG, T. (1990). Cyclooxygenase is an immediate-early gene induced by interleukin- 1 in human endothelial cells. J. Biol. Chem. 265, 10805-10808.

MATA M., JIN, C.F., and FINK, D.J. (1993). Axotomy increases CNTF receptor mRNA in rat spinal cord. Brain Res. 610, 162-165.

MCCRAY, P.B., ARMSTRONG, K., ZABNER, J., MILLER, D.W., KORETZKY, G.A., COUTURE, L., ROBILLARD, J.E., SMITH, 
A.E., and WELSH, M.J. (1995). Adenoviral-mediated gene transfer to fetal pulmonary epithelia in vitro and in vivo. J. Clin. Invest. 95, 2620-2632.

MESSINA, L.M., PODRAZIK, R.M., WHITEHILL, T.A., EKHTERAE, D., BROTHERS, T.E., WILSON, J.M., BURKEL, W.E., and STANLEY, J.C. (1992). Adhesion and incorporation of lacZ-transduced endothelial cells into the intact capillary wall in the rat. Proc. Natl. Acad. Sci. USA 89, 12018-12022.

MESSINA, L.M., WELLING, T.H., SARKAR, R., SHANLEY, C.J., and STANLEY, J.C. (1995). Gene therapy for vascular disease. In Advances in Surgical Gene Therapy. D.K. Anderson, S.E. Raper, L.M. Messina, and J.S. Economou, eds. (World Medical Press, Cedar Knolls, NJ) pp. 27-60.

MILLAN, J.L. (1986). Molecular cloning and sequence analysis of human placental alkaline phosphatase. J. Biol. Chem. 261, 3112-3115.

MULLER, D.W., GORDON, D., SAN, H., YANG, Z., POMPILI, V.J., NABEL, G.J., and NABEL, E.G. (1994). Catheter-mediated pulmonary vascular gene transfer and expression. Circ. Res. 75, 1039-1049.

NABEL, E.G., and NABEL, G.J. (1994). Complex models for the study of gene function in cardiovascular biology. Annu. Rev. Physiol. 56, $741-761$.

OOBOSHI, H., WELSH, M.J., RIOS, C.D., DAVIDSON, B.L., and HEISTAD, D.D. (1995). Adenovirus-mediated gene transfer to cerebral blood vessels in vivo. FASEB J. 9, 134a (Abstr.).

ROESSLER, B.J., HARTMAN, J.W., VALLANCE, D.K., LATTA, J.M., JANICH, S.L., and DAVIDSON, B.L. (1995). Inhibition of interleukin-1-induced effects in synoviocytes transduced with the human $I-1$ receptor antagonist cDNA using an adenoviral vector. Hum. Gene Ther. 6, 307-316.

SIMUN, R.H., ENGELHARDT, J.F., YANG, Y., ZEPEDA, M., WEBER-PENDLETON, S., GROSSMAN, M., and WILSON, J.M. (1993). Adenovirus-mediated transfer of the CFTR gene to lung of nonhuman primates: Toxicity study. Hum. Gene Ther. 4, 771-780.
TRIPATHY, S.K., GOLDWASSER, E., LU, M., BARR, E., and LEIDEN, J.M. (1994). Stable delivery of physiologic levels of recombinant erythropoietin to the systemic circulation by intramuscular injection of replication-defective adenovirus. Proc. Natl. Acad. Sci. USA 91, 11557-11561.

WAHL, S.M., ALLEN, J.B., DOUGHERTY, S., EVEQUOZ, V., PLUZNIK, D.H., WILDER, R.L., HAND, A.R., and WAHL, L.M. (1986). T lymphocyte-dependent evolution of bacterial cell wall-induced hepatic granulomas. J. Immunol. 137, 2199-2209.

YANG, Y., NUNES, F.A., BERENCSI, K., FURTH, E.E., GONZOL, E., and WILSON, J.M. (1994a). Cellular immunity to viral antigens limits E1-deleted adenoviruses for gene therapy. Proc. Natl. Acad. Sci. USA 91, 4407-4411.

YANG, Y., NUNES, F.A., BERENCSI, K., GONCZOL, E., ENGELHARDT, J.F., and WILSON, J.M. (1994b). Inactivation of E2a in recombinant adenoviruses inproves the prospect for gene therapy in cystic fibrosis. Nature Genet. 7, 362-369.

YAO, S.N., FARJO, A., ROESSLER, B.J., DAVIDSON, B.L., and KURACHI, K. (1996). Adenovirus-mediated transfer of human factor IX gene in immunodeficient and normal mice: Evidence for persistence of viral genome and prolonged transgene expression in vivo. Viral Immunol. 9, 141-153.

Address reprint requests to: Dr. Louis M. Messina University of California, San Francisco Vascular Surgery 505 Parnassus Ave., M488 San Francisco, CA 94143-0222

Received for Publication April 4, 1996; Accepted after Revision July 2, 1996. 
This article has been cited by:

1. J Yan, G L Tang, R Wang, L M Messina. 2005. Optimization of adenovirus-mediated endothelial nitric oxide synthase delivery in rat hindlimb ischemia. Gene Therapy 12:22, 1640-1650. [CrossRef]

2. Teik Kok Ho, Vineeth Rajkumar, Dame Carol Black, David Abraham, Daryll Baker. 2005. Critical Limb Ischemia Classification and Therapeutic Angiogenesis. International Journal of Angiology 14:2, 49-59. [CrossRef]

3. Baohong Cao, John R. Mytinger, Johnny Huard. 2002. Adenovirus mediated gene transfer to skeletal muscle. Microscopy Research and Technique 58:1, 45-51. [CrossRef]

4. Dennis Hartigan-O'Connor, Jeffrey S. Chamberlain. 2000. Developments in gene therapy for muscular dystrophy. Microscopy Research and Tecbnique 48:3-4, 223-238. [CrossRef]

5. Enyu Imai, Yoshitaka Isaka. 1998. Strategies of gene transfer to the kidney. Kidney International 53:2, 264-272. [CrossRef] 